\title{
Methylene Blue for Treating Vasoplegic Syndrome During Liver Transplantation: A Bolus Dose or Continuous Infusion?
}

\author{
Ceren Gunt, Nedim Çekmen \\ Güven Hospital Department of Anesthesiology and Intensive Care, Ankara, Turkey.
}

\section{Corresponding Author: \\ Dr. Ceren Gunt \\ Email: guntceren@gmail.com}

This is an Open Access article distributed under the terms of the Creative Commons Attribution License (creativecommons.org/ licenses/by/3.0).

Received : December 15, 2018

Accepted : May 11, 2019

Published : June 15, 2019

\begin{abstract}
Background: Role of methylene blue in vasopressor-resistant hypotension during liver transplantation has limited literature. Case Report: A 60-year-old man who had vasoplegic syndrome during liver transplantation is discussed in this case report. His pre-operative evaluation was normal. While it was expected that arterial blood pressure would be in normal range at 190 min after portal vein reperfusion, severe hypotension recurred under the high dose vasopressor treatment. Observed hypotension along with hemodynamic findings suggested vasoplegic syndrome. Therefore, $2 \mathrm{mg} / \mathrm{kg}$ of methylene blue was administered. The arterial blood pressure showed improvement immediately after methylene blue administration. The vasopressors were gradually reduced, and the operation completed uneventfully, the patient was transferred to the intensive care unit. Five minutes after the admission, cardiac arrest was witnessed. The cause of cardiac arrest was assumed that the previously infused methylene blue significantly decayed and per se vasopressor was ineffective in maintaining the hemodynamic stability of this patient. The patient was resuscitated successfully and discharged to the service on postoperative day 4. Conclusion: Infusion of methylene blue following a bolus dose could be beneficial in maintaining hemodynamic stability when vasoplegic syndrome develops in liver transplantation.
\end{abstract}

Keywords: Hypotension, Liver Transplantation, Methylene Blue, Portal Vein, Vasoconstrictor Agents.

\section{Introduction}

Studies related to vasoplegic syndrome and use of methylene blue (MB), which is used as an alternative treatment in vasopressor-resistant hypotension, during liver transplantation are limited [1]. Existing case reports stated wide variations in dose and administration [2-4]. Albeit a single dose of methylene blue given in this case is higher than the single doses published in the literature, sustained hemodynamic improvement seen in lower doses that was published isn't monitored in this case $[3,4]$. Currently there is no consensus or dose recommendation for $\mathrm{MB}$ use during liver transplantation leading to the presentation of this case, for which written consent was obtained from the patient for publication.

\section{Case Report}

A 60-year-old male patient $(150 \mathrm{~cm}, 79 \mathrm{~kg})$ who developed hepatocellular carcinoma in the setting of hepatitis B virus (HBV) infection was presented for orthotopic liver transplantation. In the preoperative evaluation of the patient, the laboratory values were slightly impaired (AST: $105 \mathrm{U} / \mathrm{L}$, ALT: $50 \mathrm{U} / \mathrm{L}, \mathrm{INR}: 1.7)$. The model for end-stage liver disease score was 21 . He had been taking spironolactone, tenofovir, and furosemide tablets. The transthoracic echocardiography revealed a $63 \%$ ejection fraction. The systolic functions of the ventricles and myocardial perfusion scintigraphy were observed within normal limits. A radial artery cannulation was performed before induction. 
In addition to standard monitors, cardiac output (CO), systemic vascular resistance (SVR), stroke volume (SV), stroke volume variation (SVV), and pulse pressure variation (PVV) were measured prior to induction with a pause intermittent contour cardiac output (PICCO, PULSION Medical Systems). Rapid sequence induction was performed with $0.5 \mathrm{mg} / \mathrm{kg}$ etomidate and $1 \mathrm{mg} / \mathrm{kg}$ rocuronium. Parameters prior to induction were measured as anticipated [Table 1]. After induction, hypotension with decreased SVR and SV was observed. The arterial blood gas showed $\mathrm{pH}:$ 7.42, $\mathrm{pCO}_{2}: 28 \mathrm{mmHg}, \mathrm{pO}_{2}: 120 \mathrm{mmHg}, \mathrm{HCO}^{3-}: 20$ $\mathrm{mmol} / \mathrm{L}$, and $\mathrm{BE}:-4.5 \mathrm{mmol} / \mathrm{L}$. Therefore, noradrenaline infusion was initiated and the volume replacement was adjusted to keep the SVV $<13 \%$. The vasopressor dose was increased to maintain a mean arterial pressure (MAP) of $65 \mathrm{mmHg}$. Upon clamping the vena cava, the arterial blood pressure (ABP) dropped to 61/46 (53) $\mathrm{mmHg}$ [Fig.1], the SVR decreased from $1050 \mathrm{dyn} \cdot \mathrm{s} \cdot \mathrm{cm}^{-5}$ to 550 dyn $\cdot \mathrm{s}^{\cdot} \mathrm{cm}^{-5}$ [Fig. 2] and SV from $42 \mathrm{~mL}$ to $36 \mathrm{~mL}$. The nor-adrenaline dose was increased up to $3 \mu \mathrm{g} / \mathrm{kg} / \mathrm{min}$, in addition to 2 units of erythrocyte suspension (ES), 2 units of fresh frozen plasma (FFP) replacement, a total of $5000 \mathrm{~mL}$ of fluid was administered to the patient. During portal vein reperfusion (PVR), the MAP dropped more than $30 \%$, and in turn, the dose of nor-adrenaline was increased to $5 \mu \mathrm{g} / \mathrm{kg} / \mathrm{min}$ and the dopamine infusion was initiated at $20 \mu \mathrm{g} / \mathrm{kg} / \mathrm{min}$ in $5 \mathrm{~min}$ [see Fig.3 for timeline of given vasopressors in which the PVR is marked as reference 0 min]. Hepatic artery reperfusion was completed within $64 \mathrm{~min}$ after portal vein reperfusion. At $190 \mathrm{~min}$ after PVR, severe hypotension recurred accompanied by heart rate: 100/min, CO: $4.0 \mathrm{~L} / \mathrm{min}, \mathrm{SV}: 40 \mathrm{~mL}$, SVR: 580 dyn $\cdot \mathrm{s}^{\cdot} \mathrm{cm}^{-5}$ [Fig.2], SVV: $25 \%$, and PPV: $24 \%$. Simultaneous blood gas analysis $\left(\mathrm{pH}: 7.28, \mathrm{pCO}_{2}: 47\right.$ $\mathrm{mmHg}, \mathrm{pO}_{2}: 143 \mathrm{mmHg}, \mathrm{HCO}^{3-}: 20.8 \mathrm{mmol} / \mathrm{L}$, and BE:-3.8 mmol/L) indicated no acid-base imbalance. To check the cardiac events, transesophageal echocardiography was performed, which revealed
Table 1: Change of hemodynamic parameters according to operation phases.

\begin{tabular}{|l|l|l|l|l|l|}
\hline & $\begin{array}{l}\text { SVR } \\
(\mathbf{d y n e} \\
\left.\mathbf{s n . c m}^{-5}\right)\end{array}$ & $\begin{array}{l}\text { CO } \\
(\mathbf{L} / \mathbf{d k})\end{array}$ & $\begin{array}{l}\text { SVV } \\
\mathbf{( \% )}\end{array}$ & $\begin{array}{l}\text { SV } \\
(\mathbf{m L})\end{array}$ & $\begin{array}{l}\text { Arterial blood } \\
\text { pressure } \\
(\mathbf{m m H g})\end{array}$ \\
\hline $\begin{array}{l}\text { Pre-induction } \\
\text { period }\end{array}$ & 1180 & 4.1 & 25 & 43 & $97 / 77(86)$ \\
\hline $\begin{array}{l}\text { Post-induction } \\
\text { period }\end{array}$ & 660 & 3.6 & 18 & 34 & $68 / 42(53)$ \\
\hline Unhepatic Phase & 550 & 5.0 & 19 & 36 & $61 / 46(53)$ \\
\hline $\begin{array}{l}\text { Onset of } \\
\text { vasoplegic } \\
\text { syndrome }\end{array}$ & 580 & 4.0 & 25 & 36 & $51 / 36(43)$ \\
\hline
\end{tabular}

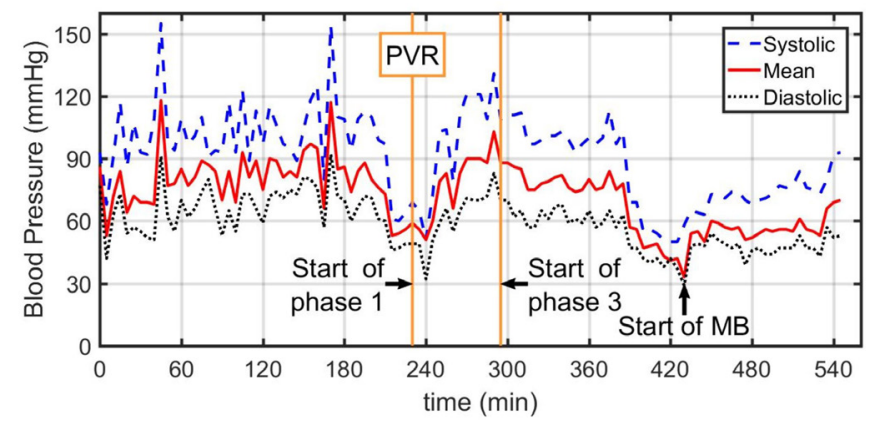

Fig.1: Change in the arterial blood pressure over time at $5 \mathrm{~min}$ intervals. The portal vein reperfusion (PVR) time is marked as the start of phase 1 and the hepatic artery reperfusion time is marked as the start of phase 3 in hemodynamic recovery [13]. The starting time of the MB bolus is marked with an upward arrow.

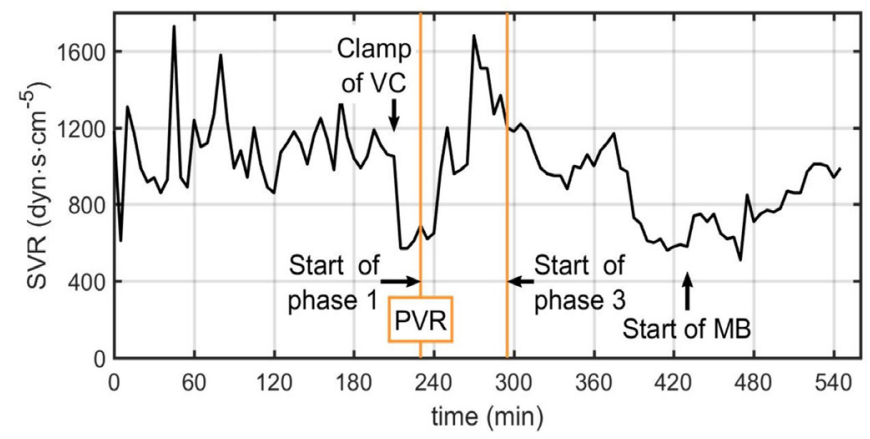

Fig.2: Change in the SVR over time at 5 min intervals. The portal vein reperfusion (PVR) time is marked as the start of phase 1 and the hepatic artery reperfusion time is marked as the start of phase 3 in hemodynamic recovery [13]. The starting time of the MB bolus is marked with an upward arrow. 
a normal bi-ventricular size and function without any evidence of myocardial infarction, pulmonary emboli, or pericardial tamponade. These findings along with hemodynamic data derived from the PICCO suggested the presence of vasoplegic syndrome. Vasopressin was not available and could not be brought into the operation room in a timely manner. Hence, $2 \mathrm{mg} / \mathrm{kg}$ of $\mathrm{MB}$ was administered for the next $30 \mathrm{~min}$, as marked in Fig. 1 and 2. The ABP showed improvement immediately after MB administration was started. Both the noradrenaline and dopamine infusions were gradually reduced. Within the first $20 \mathrm{~min}$ of $\mathrm{MB}$ administration, the dopamine infusion was completely discontinued, and the nor-adrenaline infusion went down to $3 \mu \mathrm{cg} / \mathrm{kg} / \mathrm{min}$ [Fig.3]. Next, the nor-adrenaline infusion was gradually reduced to $0.2 \mu \mathrm{cg} / \mathrm{kg} /$ min at the end of the operation, when the ABP was measured as 93/53 (70) $\mathrm{mmHg}$ and SVR was 990 dyn $\cdot \mathrm{s} \cdot \mathrm{cm}^{-5} . \mathrm{SaO}_{2}$ changed between $66 \%-82 \%$ with $\mathrm{MB}$ infusion, whereas no decrease in $\mathrm{PaO}_{2}$ (126 mmHg) and no change in carbon dioxide $\left(\mathrm{PaCO}_{2}: 44.2 \mathrm{mmHg}\right.$ ) was observed.

Over the course of the operation, 6 units of FFP, 5 units of ES, $8500 \mathrm{~mL}$ of crystalloid, 2000 $\mathrm{mL}$ colloid, and $200 \mathrm{~mL}$ of $20 \%$ albumin were administered to the patient. After the operation, the intubated patient was taken to the intensive care unit (ICU). Cardiac arrest was witnessed within $5 \mathrm{~min}$ after intensive care admission. Cardiopulmonary resuscitation was immediately started according to the European Resuscitation Council Guideline 2015 and was continued for $45 \mathrm{~min}$. As soon as possible, the cardiologist performed transthoracic echocardiography and both dimensions of the ventricles were in the normal range, indicating that the patient was not in a negative fluid balance. There was no abnormal view, such as acute right ventricular dilatation suggesting pulmonary embolus, myocardial infarction, or pericardial tamponade. Bleeding was ruled out because there was no blood in any of the surgical drains. The arterial blood gas sample

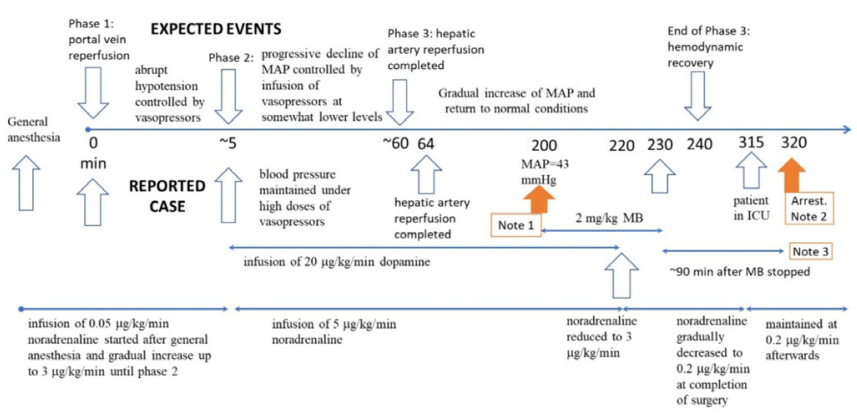

Fig.3: Expected timeline of events according to the study by Fukazawa et al. [13]. Depicted on the top, and observations and dose and time of administrated vasopressors depicted on the bottom. Note 1: TEE indicated normal bi-ventricular size and function without any evidence for MI, pulmonary emboli, or pericardial effusion. Hence, the suggested presence of vasoplegic syndrome. Note 2: TTE indicated that both ventriculi dimensions were in normal range. There was no indicator of pulmonary embolus. There was no blood in any of the surgical drains. The arterial blood gas sample was acidic due to a circulator collapse, despite the fact that the noradrenaline infusion was continued. Note 3: The patient had a cardiac arrest 90 min after discontinuing the $M B$ infusion. The effect of $M B$ was expected to decrease significantly after 40 min according to Evora et al. [14].

was acidic due to a circulator collapse. The patient was resuscitated successfully, and vasopressor therapy was discontinued $26 \mathrm{~h}$ after admission to the ICU. The patient, whose acid-base balance and hemodynamics showed a stable course, was extubated at $30 \mathrm{~h}$ after admission to ICU and discharged to the service on post-operative day 4 .

\section{Discussion}

Vasoplegic syndrome, which is significantly different than post-reperfusion syndrome (PRS), is an ill-defined clinical state characterized by significant hypotension, low SVR, high or normal $\mathrm{CO}$, and increased need for fluids and vasoconstrictors $[5,6]$. The post-operative incidence in cardiac surgery is $5-20 \%$ and the incidence in liver transplantation is not clear [7]. Independent of the etiology, the mortality in the presence of vasoplegic syndrome can be as high as $50 \%[8,9]$. End-stage liver failure is characterized by hyperdynamic circulation with a high $\mathrm{CO}$ and 
low SVR, mainly due to vasodilatation in the splanchnic circulation [10]. The gradient between low systemic pressure and high portal pressure causes a significant endothelial change followed by the activation of friction force receptors, leading to an increase in endogenous nitric oxide (NO) release and cyclic guanosine monophosphate (cGMP) production [11]. This results in smooth muscle relaxation, and decreased systemic vascular tone and vasodilatation. This hemodynamic deterioration becomes more prominent, especially during liver transplantation, necessitates the use of a vasopressor, usually in the neohepatic phase and the increased activation of the guanylate cyclase system during the natural process of end-stage liver failure puts the liver transplant patient at risk of vasoplegic syndrome

Methylene blue is used as an alternative treatment in vasopressor-resistant hypotension [5]. It supports blood pressure with a two-pronged effect. It primarily reduces cGMP and NO formation by inhibiting inducible nitric oxide synthase. Second, it binds directly to soluble cGMP and inhibits it. Thereby, the decreased cGMP increases vascular smooth muscle tone, in turn, increases SVR [5]. In addition, it increases cardiac contractility, and in turn, SV and CO rise [12]. In the literature, there are limited studies on the use of methylene blue in cases of vasoplegic syndrome in liver transplantation surgery [1]. Existing case reports stated variations in dose and administration. For example, Fisher et al. reported $2 \mathrm{mg} / \mathrm{kg}$ IV bolus followed by 0.5 $\mathrm{mg} / \mathrm{kg} /$ hour infusion for 6 hours, Cao et al. reported bolus of $0.5 \mathrm{mg} / \mathrm{kg}$ within $10 \mathrm{~min}$, Cheng et al. [4] reported IV bolus at $100 \mathrm{mg}$ as single dose in one patient, and at $100 \mathrm{mg}$ iv bolus repeated twice in another patient [2-4].

Here we would like to compare our observations with the expected normal course of events, as recently characterized by Fukazawa et al., who divided post-reperfusion hemodynamic recovery into 3 phases based on 715 patients [13]. The first $5 \mathrm{~min}$ after portal reperfusion is comprised of phase 1, in which an abrupt hypotension is observed. Phase 2 includes the time from $5 \mathrm{~min}$ after portal vein reperfusion to hepatic artery reperfusion, which lasts approximately $60 \mathrm{~min}$ and is characterized by a progressive decline of the MAP, hemodynamic recovery, comparable to baseline values, is observed in phase 3 . PRS occurs in phase 1, whereas a sustained MAP is expected in phase 3 . A comparison between the observed events in the presented case and expected events according to the study by Fukazawa et al. is shown in Fig.3. In the presented case, there was a sudden drop in both the SVR and MAP 190 min after PVR, without any vascular injury, despite the given high dose of vasopressors. At this stage, hemodynamic recovery should have been progressing. Instead, abrupt hypotension followed by continuous deterioration and observed hemodynamic parameters on the PICCO suggested vasoplegic syndrome. As stated in the case section, due the absence of vasopressin or its analogue, an intravenous bolus of $2 \mathrm{mg} / \mathrm{kg}$ $\mathrm{MB}$ was administered within $30 \mathrm{~min}$ in addition to vasopressor treatment as a last resort.

Following the start of MB, an increase in both the MAP [Fig.1] and SVR [Fig.2], similar to reported prior cases with different doses was observed [2-4]. Since there are limited studies on the use of $\mathrm{MB}$ in vasoplegic syndrome developed during liver transplantation, there are no recommended doses, and there are significant side effects, MB administration was discontinued after the hemodynamic parameters improved; however, the infusion of noradrenaline was continued. The operation was completed uneventfully, and the patient transferred to the ICU. Cardiac arrest occurred about 5 min after being transferred into the ICU, or about 90 min after stopping the bolus MB [Fig. 3, note 3]. On the other hand, in heart surgery patients, MB plasma levels were reported to decrease sharply after $40 \mathrm{~min}$ and continuous infusion after a bolus dose was recommended [14]. MB may not have been rapidly converted to leucomethylene blue by methemoglobin reductase, 
as it is expected in normal physiology, due to the effect of surgery and general anesthesia on enzyme metabolism, as well as individual variations. Accordingly, the actual MB decay time may have been different than $40 \mathrm{~min}$, depending on individual factors. Hence, we speculate that the cardiac arrest happened in this patient because the previously infused MB significantly decayed and noradrenaline was ineffective in restoring the SVR. Therefore, an infusion of MB after a bolus dose would have been helpful in maintaining the hemodynamic stability of this patient. More importantly, clinical studies to determine the dose recommendations of $\mathrm{MB}$ should be conducted to improve the outcomes of patients with vasoplegic syndrome during liver transplantation, which has a very high mortality rate.

\section{Conclusion}

MB should be considered in the treatment of vasoplegic syndrome associated with liver transplantation and bolus dose improving hemodynamics should be followed by an infusion to maintain hemodynamic stability for a longer period of time, especially when an alternative treatment (such as vasopressin) is absent.

Contributors: CG: manuscript writing, patient management; NC: manuscript editing, patient management. CG will act as guarantor. Both authors approved the final version of this manuscript.

Funding: None; Competing interests: None stated.

\section{References}

1. Koelzow H, Gedney JA, Baumann J, Snook NJ, Bellamy $\mathrm{MC}$. The effect of methylene blue on the hemodynamic changes during ischemia reperfusion injury in orthotopic liver transplantation. Anesth Analg. 2002;94:824-829.

2. Fischer GW, Bengtsson Y, Scarola S, Cohen E. Methylene blue for vasopressor-resistant vasoplegia syndrome during liver transplantation. E. J Cardiothorac Vasc Anesth. 2010;24(3):463-466.

3. Cao Z, Gao Y, Tao G. Vasoplegic syndrome during liver transplantation. Anesth Analg. 2009;108(6):1941-1943.

4. Cheng SS, Berman GW, Merritt GR, Hendrickse A, Fiegel MJ, Teitelbaum I, et al. The response to methylene blue in patients with severe hypotension during liver transplantation. J Clin Anesth. 2012;24(4):324-328.

5. Hosseinian L, Weiner M, Levin MA, Fischer GW. Methylene blue: Magic bullet for vasoplegia? Anesth Analg. 2016;122(1):194-201.

6. Xu ZD, Xu HT, Yuan HB, Zhang H, Ji RH, Zou Z, et al. Postreperfusion syndrome during orthotopic liver transplantation: A single-center experience. Hepatobiliary Pancreat Dis Int. 2012;11(1):34-39.

7. Jang DH, Nelson LS, Hoffman RS. Methylene blue for distributive shock: a potential new use of an old antidote. J Med Toxicol. 2013;9(3):242-249.

8. Huet O, Chin-Dusting. JP. Septic shock: Desperately seeking treatment. Clin Sci. 2014;126(1):31-39.

9. Akhondi M, Sabzevari A, Imannezhad S, Rahadari A. Efficacy of Methylene blue on vasoplegic syndrome. Rev Clin Med. 2016;3(2):69-72.

10. Bolognesi M, Di Pascoli M, Verardo A, Gatta A. Splanchnic vasodilation and hyperdynamic circulatory syndrome in cirrhoss. World J Gastroenterol. 2014;20(10):2555-2563.

11. Bezinover D, Kadry Z, Uemura T, Sharghi M, Mastro AM, Sosnoski DM, et al. Association between plasma cyclic guanosine monophosphate levels and hemodynamic instability during liver transplantation. Liver Transpl. 2013;19(2):191-198.

12. HaMBond J, Balligand JL. Nitric oxide synthase and cyclic GMP signaling in cardiac myocytes: from contractility to remodeling. J Mol Cell Cardiol. 2012;52(2):330-340.

13. Fukazawa K, Yamada Y, Gologorsky E, Arheart KL, Pretto EA. Hemodynamic recovery following postreperfusion syndrome in liver transplantation. J Cardiothorac Vasc Anesth. 2014;28(4):994-1002.

14. Evora PR, Ribeiro PJ, Vicente WV, Reis CL, Rodrigues $\mathrm{AJ}$, et al. Methylene blue for vasoplegic syndrome treatment in heart surgery: fifteen years of questions, answers, doubts and certainties. Rev Bras Cir Cardiovasc. 2009;24:279-288. 